\title{
LOS ESPANTOLES PINTADOS POR SÍ MISMOS (1843-1844): UNA MIRADA MASCULINA AL UNIVERSO FEMENINO.
}

\author{
M. a Isabel Jiménez Morales \\ Universidad de Málaga. España.
}

Últimamente venimos asistiendo a un proceso de recuperación del papel de la mujer en todos los ámbitos de la cultura. Las investigaciones acerca de este tema se multiplican hoy día y los trabajos que intentan fijar el retrato de la mujer a través de la literatura de todos los tiempos no son, por tanto, una excepción. El argumento dominante esgrimido por todos los estudiosos y defensores del "bello sexo" fue y es el de su forzada invisibilidad histórica.

El acercamiento a la mujer no se produjo por vez primera en este siglo, ya en los precedentes se intentó fijar su retrato, aunque en un principio, casi en exclusividad, desde una óptica masculina'. Sólo en el último tercio del siglo XIX comenzaría, tímidamente aún, a ser la mujer objeto y sujeto literarios gracias a iniciativas tan valiosas como la de la madrileña Adela Ginés y Ortiz, quien con sus Apuntes para un álbum del bello sexo quiso elaborar -ella misma lo dice en su "Prólogo"- una "galería de retratos morales con los caracteres más comunes" ${ }^{2}$; o a la de Faustina Sáez de Melgar, cuya obra pretendía presentar a la mujer tal como es, "lo mismo en España que en Portugal, nuestra hermana, que en América y en Filipinas, nuestras hijas" ${ }^{3}$.

Centraré mi análisis en la centuria pasada, aunque debo advertir que no he elegido a la mujer de la literatura romántica pues, por esa añoranza del pasado medieval mitificado, solía aparecer como musa, heroína o virgen, des- 
virtuándose así su faceta más real, su particular historia ${ }^{4}$. Mi estudio será una reflexión de la imagen de la mujer en la literatura de corte realista, concretamente en el Costumbrismo, género no siempre bien considerado por la críticas. Éste encontró su época dorada en el Romanticismo histórico, especialmente a partir de la publicación del Semanario Pintoresco Español, cuyo primer número aparece en abril de 1836, y del auge de las fisiologías, pero se prolongó a lo largo de todo el siglo XIX, dando ejemplos nada desdeñables bajo lo que todos conocemos como Realismo y Naturalismo.

Únicamente me detendré en el estudio de Los españoles pintados por sí mismos ${ }^{6}$, la más famosa manifestación de este género, la obra que inauguró el cultivo del costumbrismo en nuestro país, a semejanza de lo sucedido años antes en Inglaterra o Francia ${ }^{7}$. Comenzó a publicarse por entregas en los últimos meses de 1842, y apareció en dos volúmenes entre 1843 y 1844, siendo su impresor Ignacio Boix. Inmediatamente, por el deseo de fijar la realidad circundante, rápida a desaparecer, y de dejar constancia de aquellas costumbres autóctonas, originales y genuinas, intentando salvaguardarlas de tanta influencia foránea que soportaba el país; inmediatamente -decía-, Los españoles pintados por si mismos se convirtió en un libro de actualidad, tanto por la talla de sus colaboradores como por el espíritu que latía en la obra: fijar la imagen cambiante de la España de entonces. Los noventa y ocho tipos elegidos, presentados sin división sistemática alguna, aspiraban a ello.

Sólo un tipo de la colección, el retratado por El Solitario, contravenía el principio básico del costumbrismo: la contemporaneidad; al tiempo que el objetivo del libro: pintar los tipos que pululaban en la España contemporánea. La celestina es una recuperación del personaje medieval, de tanto sabor literario. Cuando se lee esta entrega se aprecia el ambiente del pasado que, incluso, se intenta fijar reproduciendo los modos lingüísticos de siglos anteriores con la fabla, lo que, precisamente, tanto molestó a críticos prestigio$\operatorname{sos}^{8}$. Es curioso que Estébanez incumpliera tan importante cláusula, sobre todo, teniendo en cuenta que él fue uno de los pocos colaboradores de Los españoles, junto con Mesonero Romanos, a quien podríamos otorgar, sin temor a equivocarnos, el calificativo de "costumbrista".

M. Ucelay da Cal ya apuntó en 1951 la importancia de Los españoles como documento de época ${ }^{9}$, por los pormenores tan jugosos que para el estudio de la fisonomía de la vida pública y privada de los españoles de entonces ofrecían sus páginas, sobre todo en lo que atañía a la pequeña historia, tan escasamente utilizada hasta el momento. Si aparecen datos y detalles del funcionamiento de la vida en general, de la jerarquía de las clases sociales, de las profesiones de los españoles de aquellas décadas, imagínense el importante testimonio que estas páginas representan para el estudio de un 
tema tan olvidado como el de las condiciones de vida de las mujeres del pasado. El acercamiento al universo femenino que retrataron estos escritores, su mirada cargada de un interesante deseo de posteridad, hacen posible que hoy conozcamos algo mejor la anónima existencia femenina. A ello se va a dedicar esta ponencia: a poner de manifiesto cómo vivían las mujeres, qué nivel cultural tenían, en qué trabajaban o cómo eran vistas por los varones.

En un acercamiento a los escritores que retrataron en la obra tipos femeninos, aunque ello no implique hacer una valoración estética de cada uno, comprobamos que de los cincuenta y un colaboradores de la colección costumbrista, tan sólo veinte esbozaron veintisiete aspectos diferentes de la mujer decimonónica ${ }^{10}$. Obviamente, algunos de ellos repitieron en el retrato femenino; gozando, la mayoría, de un notable prestigio en la época. Recordemos a Mesonero Romanos, Estébanez Calderón, Rodríguez Rubí, Hartzenbusch, Bretón de los Herreros, etc. Tan sólo algunos autores eran menos conocidos, en esta tesitura se encontraban José M.a Tenorio, Juan Pérez Calvo y el Dr. Pedro Recio, cuyo nombre, aventura M. Ucelay da Cal, podría ser el seudónimo de un médico del momento, Agustín Recio".

Todos estaban relacionados directa o indirectamente con el mundo de la cultura en el sentido amplio de la palabra, con la política, el periodismo, la literatura, etc., siendo su nivel cultural, en consecuencia, alto. Entre ellos se cuentan varios catedráticos, políticos, diplomáticos, bibliotecarios, académicos, eruditos... Pertenecientes todos a las clases privilegiadas del país, quienes reproducían, como veremos a continuación, los cánones y estereotipos sociales del momento, especialmente si se trataba de esbozar el retrato del bello sexo.

Nacieron en Madrid muchos de ellos, y quienes no lo hicieron, por unas u otras circunstancias, relacionadas casi siempre con sus cargos políticos, públicos o literarios, terminaron estableciendo su residencia o pasando largas temporadas en la capital del reino. De ahí, que los tipos madrileños fuesen los elegidos preferentemente por quienes colaboraron en la obra.

Se desprende del elenco de escritores que su editor, Ignacio Boix, pretendía recoger en las páginas del libro a lo más granado de su época, reunir a todas las generaciones literarias del momento, cuyos representantes habían nacido en un dilatado período de tiempo comprendido entre 1769 , fecha del nacimiento del más mayor -el riojano Bretón de los Herreros-, y 1822, en la que los más jóvenes -Navarrete y Herrero- habían visto la luz en Madrid y Jerez de la Frontera, respectivamente. En consecuencia, sus ideologías politicas e ideas estéticas se incardinaban en una amplia escala: desde liberales a conservadores acérrimos; de románticos a discípulos de Moratín. Ello ayudaba a presentar una gran variedad de enfoques y a ofrecer un mejor retrato 
de la poliédrica realidad española del momento, cuya imagen, amparada en el universalismo de la obra, es la que pretendían fijar estos escritores.

Siguiendo la "Introducción" de la obra en su primera edición, fácilmente atribuible a Ignacio Boix, comprobamos que los artículos de Los españoles fueron encargados de una forma directa a sus colaboradores, de tal modo que éstos pudieran redactar los tipos con los cuales, por motivos de educación, nacimiento, afinidad, cultura, etc., se encontrasen más familiarizados. ¿¿ cumplió esta misma condición en los femeninos?

En algunos casos sí podría establecerse una relación entre el autor y el tipo encomendado. No sorprende, todo lo contrario, que una colaboración como la de la gitana, se le encargue a Sebastián Herrero, andaluz de Jerez de la Frontera; que la coqueta corra a cargo de Ramón de Navarrete, escritor fecundo que introduciría en la prensa diaria de su época las crónicas del mundo elegante ${ }^{12}$; que un tipo como la celestina encabece el segundo volumen de Los españoles y que se le encomiende a un amante de la literatura medieval y de los Siglos de Oro como lo fue Estébanez; que la comadre la retrate un supuesto médico; y que la monja la pergene un catedrático como Vicente de la Fuente, cuya obra literaria fue una casi total especialización en textos históricos y religiosos... Caso aparte sería el de Gabriel Garcia Tassara, quien esbozó para la colección "La politicómana", pese a la escasez de tipos dedicados en esta obra al ámbito de la política ${ }^{13}$. ¿Quién mejor que él para retratarla cuando es de todos sabido que la preocupación política era una de sus inspiraciones literarias más importantes ${ }^{14}$ ?

Un rasgo a destacar sería el de la finalidad didáctica de la mayoría de los textos que tratan de la mujer, respetando así uno de los presupuestos del género, por el cual los escritores utilizaban los artículos para demostrar, en buena medida, sus conocimientos sobre el tema que estaban abordando ${ }^{15}$. $\mathrm{Y}$ esto lo hace Mesonero Romanos cuando habla del estado y divisiones de las casas de huéspedes en Madrid, de los precios, aseo, clasificación de los forasteros, etc.; A. Flores, cuando pone al corriente a sus lectores de las condiciones, salario y clasificación del trabajo de las cigarreras; o José de Grijalba, entre otros, al ofrecer al lector interesantes descripciones de los cuarteles y cantinas del siglo XIX.

No sólo habría que resaltar el valor didáctico de las digresiones de estos artículos. En ellos solían dar consejos a las mujeres, como si pretendiesen educarlas y formarlas moralmente. Muchos de sus artículos hacen concesiones al proteccionismo y paternalismo de las clases altas y medias del país. Por tanto, no sólo pretendían retratar, fijar el daguerrotipo femenino contemporáneo, sino encauzar el comportamiento, a través de Los españoles, de sus esposas, madres, hermanas o hijas. Valgan como ejemplos: Mesonero con su 
patrona de la casa de huéspedes o Salas y Quiroga con la viuda de un militar, quien opinaba que la literatura debía tener, por encima de todo, una misión social, de dirección y de enseñanza ${ }^{16}$.

Comenzando con el estudio de la imagen de la mujer en Los españoles pintados por sí mismos, debo apuntar en primer lugar una reflexión acerca de la clase social de los tipos elegidos. De los veintisiete retratos femeninos, hay un claro predominio de la clase popular, pues diecisiete de ellos pertenecen al pueblo llano ${ }^{17}$. Otros, _-"La coqueta", "La politicómana", "La viuda de un militar" y "La colegiala"-, aunque sus respectivos autores no den marcas sociales explícitas, pertenecen a la burguesía o a la clase superior $\mathrm{o}$, al menos, se desenvuelven, empleando un galicismo que cundió en el siglo XIX, en el "gran mundo". Pues es lógico que para que una mujer pudiera hablar de política, lucir en sociedad o asistir a un pensionado en su infancia y juventud, debía ser miembro integrante de una clase social acomodada con las licencias sociales, económicas y morales que ella conllevaba.

Hay otros tipos, tres en concreto: "La marisabidilla", "La señora mayor" y "La mujer del mundo", que comparten rasgos de diferentes clases sociales, de ahí que los escritores así lo especifiquen sirviéndose de una técnica extendidísima en la época: la de las fisiologías ${ }^{18}$, que, siguiendo procedimientos seudocientíficos, cercanos a la biología, pretendían ofrecer la clasificación global y completa de un tipo, para presentar la realidad en su totalidad. Así, la mujer del mundo, empleando un eufemismo, que el ilustre malagueño Rodríguez Rubí retrata se da en las tres clases sociales, la marisabidilla de Cayetano Rosell puede pertenecer al pueblo o a la burguesíaaristocracia y.la señora mayor de Madrazo es dividida por su autor en la aristocrática y la de clase media.

Otros tipos que tampoco tienen marca social alguna, pero que son difíciles de clasificar son la actriz, la monja y la santurrona. Sus autores se muestran indecisos, sobre todo, en los dos primeros casos, pues son artículos que denuncian la realidad artística y literario-política de la época, respectivamente. Ambos fueron redactados por espíritus críticos, en la línea del costumbrismo combativo y político de Fígaro. En el primer caso -con "La actriz"-, se apunta la pésima situación del arte escénico en España; y en el segundo, Vicente de la Fuente, utilizando la desastrosa coyuntura del país tras la desamortización de Mendizábal, con la cual su autor aprovecha para atacar las medidas impías y arreligiosas de un gobierno liberal, critica un tipo de literatura, la romántica, que tanto, y tan mal, se sirvió de personajes literarios como la monja, la abadesa, la novicia, etc.

No hay analogías, por consiguiente, con el resto de los tipos masculinos de la obra colectiva que estoy analizando. Pues si ambos-masculinos y 
femeninos- coinciden en la escasísima atención prestada a la aristocracia, los primeros dan su preferencia al retrato de la burguesía, reflejando en sus páginas todo ese florilegio de nuevas profesiones, relacionadas en su mayoría con la administración del Estado. En general, Los españoles entraba en este punto en conexión directa con lo que el decano del costumbrismo nacional -Mesonero Romanos- ya había apuntado en la década anterior en el "Prólogo" de su Panorama matritense: para que una obra reflejara moralmente la sociedad debía ofrecer al público un cuadro colorista de todas las clases sociales. Ahora bien, la atención debía fijarse de un modo especial en la clase media, pues sólo ésta, por su extensión y variedad, imprimía a las sociedades su impronta particular ${ }^{19}$.

Los tipos femeninos pertenecientes a la clase media son -como hemos podido ver- muy escasos. No se sigue, por tanto, la tendencia de los demás artículos de la colección. En este aspecto, podríamos decir que los escritores que fijaron la esencia femenina en Los españoles prefirieron dejar una imagen pintoresca, castiza y popular de las mujeres de su época. Parecía lógico que la mujer de la clase media no se reflejase con variedad de tipos, pues no existían dentro de este grupo social. Los cánones de la nueva sociedad burguesa sólo defendían un prototipo: el de la mujer entregada al cuidado del esposo y el hogar y a las funciones de reproducción biológica, ello conllevaba una mayor invisibilidad del bello sexo.

He querido percibir que en esta colección los parámetros varían según se retrate tipos masculinos o femeninos. Lo que parece ser más genuino entre los varones -la burguesía - no cumple las mismas condiciones entre las mujeres, pues en los tipos femeninos todo se muestra más inmovilista, más conservador. La retina de nuestros costumbristas parece sentirse más atraída por las clases populares, aunque cada vez fuesen menores en número y calidad, que por las medias, que progresivamente absorbían y desdibujaban los rasgos propios de las clases extremas ${ }^{20}$.

Como consecuencia de esta pintura generalizada, escritores como Manuel Bretón o Sebastián Herrero alabarán a sus tipos -la lavandera y la gitana, respectivamente- por su originalidad y por mantenerse impermeables a tantas influencias negativas y extranjeras. Así lo especifica el jerezano Herrero:

Nuestros tipos se hallan averiados, y se necesitan ojos de lince y un enorme catalejo para descubrir nuestras peregrinas costumbres populares entre las insulsas costumbres extranjeras, y nuestros antiguos caracteres entre los caracteres de hoy [...] Los gitanos son impermeables sin que les hagan mella las revoluciones ni los descortece esa arrogante matrona llamada civilización ${ }^{21}$. 
Y José M. a Tenorio, autor de "La casera de un corral", volverá a apuntar al final de su artículo, para apoyar la originalidad de su tipo y de otros muchos del país, la inamovilidad de las costumbres en las clases populares: "Ves cómo en las raíces del árbol social no penetran los embates políticos" (p. 177). Pensaban estos escritores, como Estébanez Calderón, que la autenticidad y originalidad de su época ya sólo podía encontrarse en las clases populares.

Otra de las características generales de los tipos femeninos de Los españoles es el escenario en el que éstos se desenvuelven. En la mayoría de los casos es, obviamente, la gran ciudad, a excepción de la cantinera o la posade$r a$, quienes, por su trabajo, pueden desenvolverse en pueblos, cuarteles, frentes bélicos, despoblados, etc. Son éstos, sin embargo, una excepción. Los tipos femeninos de Los españoles -eminentemente urbanos- están, en este aspecto, en la misma línea que los masculinos, coincidiendo en la orientación de todo el costumbrismo nacional. No estoy, por tanto, de acuerdo con la afirmación de $\mathrm{H}$. Juretschke cuando considera el costumbrismo como un movimiento de búsqueda del personaje "no urbano", del paisaje idealizado y de los pueblos del pasado, en contraste con la novela realista que se detiene en reflejar el mundo de la ciudad ${ }^{22}$.

La gran urbe en la que se darán cita será Madrid. Las provincias quedan desdibujadas, salvo en los ejemplos de "La casera de un corral", que es un tipo sevillano y "La gitana", que tiende a apuntar hacia Andalucía. Es significativo que descuelle de la norma general de Los españoles la región andaluza. Sus autores simplemente estaban indicando una interesante tendencia de la época: el andalucismo imperante en la sociedad española. De todas las regiones del país, Andalucía era vista con ojos complacientes, pues sus autores seguían la línea de la recuperación de lo más castizo y pintoresco, que estaba a punto de desaparecer por tanta influencia foránea, y que solía recaer en el Mediodía español. Entramos en esas contradicciones del género: quería evitarse el casticismo cultivado especialmente por escritores extranjeros y se caía en las mismas demasías pintoresquistas al fijar esa España de pandereta cuyos encantos seducían con tanta facilidad a nuestros autores.

Otro rasgo a tener en cuenta para la mejor comprensión del universo femenino de esta época es el de la educación de las mujeres. Por las páginas de Los españoles puede constatarse cuál era el nivel cultural de la mujer en el primer tercio del XIX. Todos los tipos femeninos retratados presentan un nivel bajísimo de instrucción, o nulo, en la mayoría de los casos, pues no suele haber referencias de ningún tipo a aquélla ${ }^{23}$. Estos costumbristas no hacían más que reflejar la situación de la mujer decimonónica. No podemos olvidar que a mediados del siglo, el $86 \%$ de ellas seguía siendo analfabeto. 
Las únicas excepciones en la obra serán la marisabidilla, la politicómana y la colegiala. Estos tres tipos ostentan un nivel medio-bajo de instrucción y precisamente por ello serán ridiculizadas en el caso de los dos primeros tipos por los autores que decidieron perfilar sus retratos, entre otras razones por presentar la terrible anomalía de dedicarse a tareas tan poco acordes con su sexo, como eran en la época la literatura y la política. ¡Qué mayor pecado para una mujer de entonces que pergeñar algunos versos al estilo romántico o atreverse a opinar, en público, de política! En "La marisabidilla" y "La politicómana" se parodia su educación y sus lecturas, causas de estragos tan alarmantes como el ateísmo, la falta de belleza, la masculinización de sus rasgos o la pérdida de su femineidad, cuya consecuencia última podía ser la soltería o, si habían usado del vínculo matrimonial, el abandono de los deberes propios de su sexo, llevando la infelicidad al matrimonio y al hogar ${ }^{24}$.

Sólo he encontrado una interesante cita en "La maja" donde aparece un comentario irónico a su falta de instrucción y, consecuentemente, a su bajo nivel de exigencias culturales:

La Maja concurre pocas veces al teatro, y esto en días de fiesta y cuando la empresa ha condecorado su cartel con gruesas letras y espantosos figurones. [...] Todos los actores la parecen buenos cuando gritan, y si en la comedia hay tiros y ladrones es una excelente comedia. (p. 215)

Aquí sí podría aludirse a ese menosprecio del que habla M. Ucelay en su clásico estudio ${ }^{25}$. Manuel M.a de Santa Ana se burla de la falta de instrucción de un tipo tan castizo como la maja, que le impide discernir la calidad de la chabacanería; pero hay otros autores, como Hartzenbusch o García Tassara, que se muestran algo más comprensivos: esos tipos femeninos que retratan no son del todo culpables de su ignorancia, son el mero resultado de la educación recibida. ¿Pretendían con estos argumentos deterministas criticar a los tipos o disculpar sus muchos desaciertos reivindicando una profunda y cualitativa instrucción? ¿Había en ellos un ataque a esas otras mujeres que habían educado a las que aparecían retratadas en Los españoles? Cuestiones difíciles de resolver. La única certeza es que las mujeres tenían el nivel pésimo que debían tener en una sociedad que hasta el último tercio del siglo XIX no comenzó a defender el derecho de la mujer a la instrucción, y siempre con razones bastante tibias ${ }^{26}$.

El mundo laboral femenino que despliega esta interesante obra colectiva ante nuestros ojos ofrece una serie de oficios, hoy algunos completamente olvidados. Pese a su considerable variedad, son, en número, muy inferiores a los que recrean los tipos masculinos de la misma colección. Son presentados en su mayoría con detenimiento y minuciosidad, con el pincel colorista de quien quiere fijarlos en la memoria colectiva. Hay, sin embargo, 
concesiones a la censura en algunos trabajos domésticos, como el que desempeñan las nodrizas, que es mal visto por Bretón de los Herreros cuando se las contrata para que las madres jóvenes puedan dedicarse a brillar en sociedad $y$ a divertirse. Se produce, por tanto, un veto al trabajo femenino en los casos en que se transgrede la norma de la sociedad burguesa.

Todos los trabajos que se reflejan en la obra son desempeñados, a su vez, por las mujeres pertenecientes al pueblo.-no sucede lo mismo con los masculinos-. Los tipos de la aristocracia y de la burguesía reflejan actitudes sociales: coqueta, santurrona; estados civiles: viuda de un militar, niveles culturales: marisabidilla, politicómana; vicios: mujer del mundo..., pero nada de trabajo, pues no entraba en los esquemas ideológicos de los escritores de la época.

La mujer de cierto nivel social sólo centraba su función en el cuidado del hogar y en la reproducción biológica, por lo que se les vedaba acceder al mundo laboral. El trabajo estaba "permitido" socialmente a las casadas de baja condición social que debían ayudar al sostenimiento de la familia cuando el salario del marido era exiguo o los hombres no querían trabajar (ello se ve en "La cigarrera"), con cuyo sueldo escaso mantenían a esposos y padres; a las huérfanas y viudas, pero siempre por necesidad; o a las solteras que necesitaban de un apoyo económico para vivir, aunque abandonaban su empleo en cuanto se casaban; o a aquel Esto se refleja a la perfección en Los españoles pintados por si mismos.

Los trabajos que se recrean están, en su mayoría, relacionados con la producción de tipo familiar: castañera, prendera; con el "decoro": comadrona; con las manifestaciones artísticas: actriz; con la menestralía, especialmente de las fábricas de tabaco repartidas por tantas ciudades de España, que emplearían a miles de cigarreras; $y$, muy en especial, con el servicio doméstico: ama del cura, criada, nodriza, ama de llaves, lavandera, doncella de labor, patrona de huéspedes, posadera..., ya que el trabajo doméstico en las ciudades empleaba a un gran número de mujeres. Son, evidentemente, trabajos modestos, sencillos, "femeninos" en la mayoría de los casos, para los que no se necesitaba un especial desarrollo intelectual ni una educación esmerada. Son los típicos oficios de las mujeres del pueblo del siglo pasado.

Quiero reincidir en el valor documental de estos textos. A través de estas páginas costumbristas podemos saber, por ejemplo, cómo eran contratadas las lavanderas del XIX, o cuál era el horario de la jornada laboral y condiciones de trabajo de una cigarrera; qué hacían con sus hijos las nodrizas cuando debían amamantar a los de otras mujeres, o cuál era la situación de las actrices. Tienen estos artículos la importancia de ser, en muchas ocasiones, los únicos testimonios escritos acerca de estos oficios, siendo referencia obli- 
gada para el historiador especializado en la centuria precedente a la hora de una mejor reconstrucción del pasado.

Pero, ¿`cómo era, en realidad, retratada la mujer? ¿Cuáles sus virtudes y defectos? En cuanto a las críticas o alusiones negativas, Mesonero Romanos apunta la debilidad de corazón y el exceso de confianza en el hombre de "La patrona de huéspedes". El cálculo y el interés parecen ser cualidades de tipos relacionados con el servicio doméstico: "La patrona de huéspedes", "El ama de llaves" y "La doncella... de labor". Frlvolas, insensibles y antinaturales son las madres "de buen tono" que abandonan a sus hijos en manos de "La nodriza" para ir al teatro ${ }^{27}$. Chismosas y dadas a la murmuración son tipos como "La castañera", "La criada", "La santurrona", "La lavandera" y "La comadre". Horrorosa y hombruna, "La politicómana"; mentirosa, "La actriz"; débil de carácter y fácilmente influenciable, "La viuda de un militar". Fea, toda aquélla que "haya cruzado la línea equinoccial" -que a la sazón eran los cuarenta años- "sin haber celebrado primeras o segundas nupcias", dice Hartzenbusch ${ }^{28}$. Hipócrita y sin opinión propia es "La coqueta"; excesiva, cuando ejerce de "santurrona". Varoniles y masculinas, si eclipsan al marido, teniendo ejemplos en "La cantinera, "La casera de un corral" y "La posadera". Siempre son coquetas -nos dirá Ramón de Navarrete-, y perderán su femineidad y belleza en el preciso instante en que abandonen las tareas del hogar y del matrimonio para dedicarse a la política o a la literatura, como puede contemplarse en "La politicómana" o en "La marisabidilla".

¿Cuáles son sus virtudes? Se nos presentan naturales y sin artificios en "La lavandera" y "la gitana", por conservar sus rasgos más genuinos del pueblo, como ya hemos visto antes. Inteligente es "La doncella... de labor", y trabajadora es "La cigarrera".

Hay pocos tipos femeninos "anómalos", pero el que es retratado con mayor malicia es el de la politicómana, donde su autor se despacha a su sabor en improperios e insultos. Puede verse un único pero esclarecedor ejemplo en la descripción de su físico, horrible, pero malgastado aún más por su indeseable e insana dedicación:

Su frente no es aquella frente en que Byron vela trasparentarse los pensamientos de amor, sino una frente preñada como la de un íncubo $y$ arrugada como la de un viejo. Sus ojos no son de esos ojos en que otro poeta romántico vela oscilar la llama del amor como en una lámpara alimentada con esencias, sino unos ojos desencajados como los de un energúmeno y amarillentos como los de un bilioso. Su boca no es una boca entreabierta con la sonrisa de la voluptuosidad, es una boca entreabierta sí, pero entreabierta como la de un orador impaciente por el turno de la palabra. Sus facciones, todas, son facciones rfgidas y ocasionadas a las caricaturas de la irritabilidad tribunicia, no hay duda en ello. La manía de la política aterra el rostro, especialmente en la 
mujer. Lavater hubiera confirmado su sistema con la observación de la mujer política. El cráneo no se lo hemos observado a ninguna de ellas, pero será desigual y protuberante como una cantera por pulir, y Gall y Spurzhein habrían pasado horas enteras con las manos en la cabeza de mujer política. Decididamente, la fisonomía de la mujer política no ofrece los caracteres de la belleza femenina. (p. 196)

Pese a la aparente visión negativa de las mujeres en Los españoles, el tono crítico y la intención paródica no son predominantes en sus páginas. Todos esos rasgos que hoy pueden parecernos negativos no lo eran tanto en el XIX, pues se limitaban a repetir los clichés de la época, que eran claramente perjudiciales para el "sexo débil", pero sobre todo si los contemplamos desde nuestra óptica moderna. Estos escritores reproducían una imagen femenina conforme al decoro de entonces. Por tanto, la coquetería, la debilidad, la exageración, la frivolidad, la murmuración, la hipocresía, etc., eran rasgos inherentes a la mujer. Resaltarlos en la literatura no implicaba crítica alguna por pertenecer y ser tan propios de ellas, a juicio de estos escritores.

Donde sí hay denuncia, parodia y una llamada de alerta es en esos tipos que transgredían las normas establecidas y que estaban dispuestos a trastocarlo todo desde sus más profundas raíces. Cuando una mujer se acercaba peligrosamente a la creación literaria, a la lectura o a la política, la cosa cambiaba. Por eso, Cayetano Rosell afirmará en la digresión de "La marisabidilla" que el objetivo de su artículo no era tan inocente como parecla:

Hay que hablar mal del bello sexo, es decir, de una parte de él, buscar el lado por donde flaquean algunos de sus individuos, y sacarlo a plaza, para que ellos mismos se rían y avergüencen de su ridiculez. Si mal no me acuerdo, ésta es la empresa que me han encomendado. (p. 340)

Los tipos más críticos, sin duda, son con los que sus autores querían advertir, mediante la ironía y la parodia, de lo peligrosos que eran en la mujer todo tipo de excesos, pues solían conllevar el lógico abandono de sus funciones primarias y básicas en la sociedad. Así sucede con la santurrona de Antonio Flores ${ }^{29}$ y la politicómana de Gabriel García Tassara ${ }^{30}$. La marisabidilla no llega, pese a su tono paródico inicial, a apuntar esta anomalía, pues aquélla, cuando llega a una determinada edad, se casa y abandona sus pretensiones intelectuales.

He podido comprobar, por consiguiente y como resumen, varios enfoques en Los españoles pintados por sí mismos con respecto a la mujer: el complaciente y pintoresco, el más abundante; y el crítico, donde predomina, evidentemente, el tono irónico y la parodia. Habría que hacer, no obstante, una precisión dentro de este último punto: la elección de tipos femeninos para denunciar los vicios y la mala situación del país, no para evidenciar defectos 
propiamente femeninos. En esta tesitura estarían "La viuda de un militar", donde Jacinto Salas y Quiroga denuncia la crisis de un país que paga poco y mal las pensiones; o "La actriz", donde el mismo autor pone de manifiesto la mala situación escénica de España; sin olvidar a "La monja", en la que Vicente de la Fuente lamenta la desamortización de Mendizabal, al tiempo que hace crítica literaria en contra del Romanticismo francés que tanto empeño puso en exagerar las escenas cotidianas de la vida monacal.

Las plumas de esta colección eran burguesas y aristocráticas y escribían para la burguesía y la nobleza. Siguiendo el objetivo primordial impuesto desde la "Introducción" -rescatar lo genuino del olvido y fijarlo en el cuadro literario-, parecía lógico que en su mayoría recreasen tipos femeninos pintorescos y tradicionales, dentro del conservadurismo del género costumbrista. En los tipos en los que no aparece crítica alguna -ya sea a la sociedad de la época o a la situación femenina del XIX-, las mujeres que se presentan a estudio serán más tradicionales, pintorescas y castizas. Mayor crítica habrá, obviamente, conforme aumente la subversión de los papeles sociales.

$\mathrm{Si}$ atendemos objetivamente a los datos, vemos que en el costumbrismo decimonónico nacional comenzó prestándose una menor atención al sexo femenino. En Los españoles pintados por sí mismos -biblia del costumbrismo del XIX en nuestro país-, tan sólo veintisiete del casi centenar de sus artículos fijaban tipos del denominado "sexo débil". Casi todos ellos estaban relacionados con la faceta más pintoresca y castiza de la mujer y pocos, muy pocos, con la crítica al deseo de instrucción o emancipación femeninas. Con el transcurso del siglo, el costumbrismo iría dedicando, con carácter de exclusividad, diferentes colecciones destinadas a la fijación de la idiosincrasia femenina, ya me he referido a algunas de ellas.

La primera, Las españolas pintadas por los españoles, ofrecía sesenta y siete tipos diferentes, aún desde una óptica masculina. Favoreciendo la diversidad de opiniones, su director, Roberto Robert, quería ofrecer a las mujeres lo que los hombres pensaban realmente de ellas. Hay, como apunta M.a Á. Ayala, un cambio acusado al centrarse esta obra en el análisis de los rasgos existenciales y psicológicos femeninos ${ }^{31}$. Los clichés que reproducen siguen siendo, no obstante, los de la sociedad burguesa patriarcal.

Entre 1872 y 1876 aparecieron los tres volúmenes de Las mujeres espanolas, portuguesas y americanas ${ }^{32}$ que trataban al bello sexo desde un enfoque más folclórico que propiamente literario, perpetuando su imagen tradicional. En la década de los ochenta, Las mujeres españolas, americanas y lusitanas pintadas por sí mismas incluía un elemento novedoso: la reivindicación de la mujer, que afloraría -lo apunta M.a Á. Ayala-, en mayor o menor medida, dependiendo del compromiso de la escritora con la consecución de un nuevo 
papel en el seno de la sociedad de finales de siglo ${ }^{33}$. Dentro del moderantismo de la época, empieza a abogarse por un perfeccionamiento intelectual y moral de la mujer y por su derecho a la instrucción, aunque con el objetivo de que reviertan sus frutos directamente en beneficio del esposo, los hijos y, en consecuencia, de toda la sociedad.

Entre ambos hitos aparecerían diez tipos femeninos en Los españoles de ogaño ${ }^{34}$, colección concebida como una segunda parte de Los españoles pintados por si mismos, de tal modo que todos los tipos que no pudieron incluirse en esta obra, "ocupan un señalado lugar en la presente", aclara su editor en las palabras que sirven de pórtico al primer volumen; y tan sólo tres en una colección de marcado carácter periodístico, en la que predominaban las escenas costumbristas: Madrid por dentro y por fuera ${ }^{35}$. Excluyo de esta rápida, pero obligada, referencia otras dos obras misceláneas de menor interés para esta investigación por reflejar en sus páginas una visión más localista y restringida al centrarse en la tipología de Valencia y Galicia, respectivamente ${ }^{36}$.

Hasta aquí esta breve recapitulación de todo un género, y una aportación más al estudio del papel de la mujer en la sociedad decimonónica española, que, espero, sirva para conocer mejor, gracias a las páginas de Los españoles pintados por sí mismos, el olvidado universo femenino, sobre el que veinte escritores diferentes lanzaron, hace ahora más de siglo y medio, su personal mirada.

\section{NOTAS}

1 Entre algunos nombres de escritores que se acercaron al universo femenino en los siglos anteriores contamos con Juan de Zabaleta y su Dia de fiesta por la maniana (1654); Juan A. Mercadal, cuando habla sobre los galanteos, diversiones y matrimonios en El Duende Especulativo sobre la Vida Civil (1761); José Clavijo y Fajardo, por sus articulos en El Pensador (1762-1767), donde enjuició la vida ociosa de las damas, las tertulias, etc.; Cristóbal Romea y Tapia, reincide en estos mismos temas en El escritor sin ttulo (1763): el despilfarro, visitas y desarreglos de la casa y la mujer; Beatriz Cienfuegos, quien se pregunta acerca de la educación femenina, en La Pensadora Gaditana (1763), etc.

2 Apuntes para un dibum del bello sexo. Tipos y caracteres de la Mujer, San Agustín del Guadalix, Ayuntamiento de San Agustín del Guadalix, 1995, p. 50. No cuento El dlbum del bello sexo o Las mujeres pintadas por st mismas (Madrid, Imp. de "EJ Panorama Español", 1843), pues, pese a su subrítulo, de las cuatro entregas conservadas, sólo una corrió realmente a cargo de una mujer: "La dama de gran tono", realizada por Gertrudis Gómez de Avellaneda. Las restantes las escribieron Antonio Flores -"La colegiala"-, Vicente Díaz Canseco - La manola"- e Inocencio Riesgo Le Grand -"La niñera".

3 "Introducción" a Las mujeres españolas, americanas y lusitanas pintadas por si mismas. Estudio completo de la mujer en todas las esferas sociales. Sus costumbres, su educación, su carácter. Influencia que 
en ella ejercen las condiciones locales y el espiritu general del pais a que pertenece. Obra dedicada a la mujer por la mujer y redactada por las mds notables escritoras bispano-americano-lusitanas bajo la dirección de la señora donia Faustina Sdez de Melgar, Barcelona, Est. Tip.-Ed. de Juan Pons, ¿1881?, p. I.

4 Vid. el artículo de A. M." Arias Cossio, "La imagen de la mujer en el Romanticismo español", en AA. VV., La imagen de la mujer en el arte español. Actas de las III Jornadas de Investigación Interdisciplinaria, Madrid, Universidad Autónoma de Madrid, 1984, pp. 113-118.

5 El costumbrismo ha recibido, con el correr del tiempo, diferentes interpretaciones. La postura crltica de la tradición espahola lo ha juzgado como "género menor", siempre supeditado a otras manifestaciones literarias mayores, como la novela, con mediocres cultivadores y con una negativa influencia sobre ésta. ( $C f f$. entre otros títulos: E. Correa Calderón, "Los costumbristas espafioles del siglo XIX", Bulletin Hispanique, LI (1949), Pp. 291-316; J. F. Montesinos, Costumbrismo y novela. Ensayo sobre el redescubrimiento de la realidad espaniola[1960], Madrid, Castalia, 1972; F. Caravaca, "Notas sobre las fuentes literarias del costumbrismo de Larra", Revista Hispdnica Moderna, XXIX, 1 (1963), pp. 1-22; J. I. Ferreras, "Novela y costumbrismo", Cuadernos Hispanoamericanos, Madrid, LXXXI, no 42 (1970), pp. 345-367; etc.) Por el contrario, los críticos norteamericanos han revalorizado el costumbrismo, pues lo han estudiado en sf mismo, ampliando los límites cronológicos y rescatando del olvido a escritores desconocidos. (Vid. R. F. Brown, La novela española. 1700-1850, Madrid, Ministerio de Educación Nacional, 1953; y C. M. Montgomery, Early Costumbrista Writers in Spain, 1750-1830, Filadelfia, University of Pennsylvania, 1931.)

6 Los españoles pintados por sí mismos, Madrid, I. Boix, Editor, 1843-1844, 2 vols. (Haré todas las citas a partir de la segunda edición: Madrid, Gaspar y Roig, Editores, 1851.)

7 Fueron antecedentes de nuestra colección la inglesa Heads of the people: or Portraits of the English drawn by Fenny Meadows. Whit original essays by distinguished writers, London, Robert Tyas, 1840-1841, 2 vols.; y la francesa: Les français peints par eux mêmes. Encyclopédie morale du dixneuvieme sizcle, Paris, L. Curmer, 1840-1842, 9 vols.

8 J. F. Montesinos, por ejemplo, dijo de este artículo que habia en sus personajes "frases de un engolamiento imposible". (Op. cit., p. 36.) Lomba y Pedraja afirmó que estaba plagado de consideraciones prolijas, retóricas y vulgares, y de "escenas que se proponen, no que se cuentan". (Vid. "Costumbristas españoles, 1800-1850", en Mariano Jose de Larra ("Figaro"). Cuatro estudios que le abordan o le bordean, Madrid, Tip. de Archivos, 1936, p. 46.)

9 Los españoles pintados por st mismos" (1843-1844). Estudio de un género costumbrista, México, El Colegio de México, 1951, p. 176.

10 Ramón de Mesonero Romanos, Manuel Bretón de los Herreros, José M.a Tenorio, José M.. de Andueza, Ramón de Navarrete, Juan E. Hartzenbusch, Antonio Flores, Tomás Rodríguez Rubí, José de Grijalba, Sebastián Herrero, Serafín Estébanez Calderón, Gabriel Garcla Tassara, Manuel M." de Santa Ana, Dr. Pedro Recio, Jacinto Salas y Quiroga, Vicente de la Fuente, Carlos García Doncel, Juan Pérez Calvo, Cayetano Rosell y Pedro de Madrazo. (Los he enumerado tal y como aparecieron en la segunda edición de Los españoles pintados por st mismos.)

11 Op. cit., pp. 243-244.

12 Vid. para mayor información la entrada de este autor en Veinticuatro diarios. Madrid, 1830-1900. Articulos y noticias de escritores españoles del siglo XIX, Madrid, C. S. I. C., 1972, vol. III, pp. 281301.

13 M. Ucelay apunta la posibilidad de que, debido a las diferentes ideologias de sus colaboradores, fuese desaconsejada por el propio editor esta polémica vertiente. Es más, los tipos -y ya no sólo este femenino- que abordan dicho tema únicamente hacen referencia directa a periodos políticos o gobiernos de épocas pasadas. Op. cit., p. 147.

14 Vid. R. Gullón, "Tassara, duque de Europa", Boletín de la Biblioteca Menéndez Pelayo, XXII (1946), p. 146. 
15 E. Rubio Cremades y M.a A. Ayala, Antologia costumbrista, Barcelona, El Albir Universal,1985, p. 27.

16 Dato apuntado por J. L. Alborg, Historia de la literatura espaniola. El Romanticismo, Madrid, Gredos, 1988, vol. IV, p. 388.

17 "La patrona de la casa de huéspedes", "La castaniera", "El ama del cura", La criada", "La nodriza", "El ama de llaves", "La lavandera", "La cantinera", "La gitana", "La celestina", "La casera de un corral", "La maja", "La doncella... de labor", "La comadre", "La posadera", "La cigarrera" y "La prendera".

18 Estas irrumpieron en el mercado editorial francés a partir de 1840, atestiguando la demanda popular que existla por la literatura de tipos. En ellas se hacfa un estudio completo de la apariencia fisica, psicología, vida, costumbres, orfgenes... de un tipo general, tomado como representativo de la clase o categoría a la que pertenecia. Ejercieron mucha influencia sobre la literatura inglesa y la espafiola de la época. Gozaron de tanto éxito que "fisiología" pasó a designar lo mismo que "costumbrismo". La única diferencia entre ambos términos es que las primeras eran visiones fraccionarias de la sociedad, sin propósito de integración, en tanto que los tipos costumbristas tenían como objetivo ofrecer una visión total del esplritu colectivo del pals. Cuando, por vez primera, se publicaron, en colaboración, varios tipos bajo un mismo epigrafe, el costumbrismo dio origen a una forma de mayor trascendencia. (Para mayor información, vid. M. Ucelay, op. cit., pp. 77-80.)

19 "Y he aquí la razon por qué en obras tales, si bien no dejen de ocupar su debido lugar las costumbres de las clases elevada y humilde, deben obtener naturalmente mayor preferencia las de los propietarios, empleados, comerciantes, literatos, artistas, y tantas otras profesiones como forman la medianía de la sociedad." "Prólogo" a Panorama matritense. Cuadros de costumbres de la capital, observados y descritos por Un Curioso Parlante, Madrid, Imp. de Repulles, 1835, p. XV.)

20 "Lo que llamamos pueblo bajo ha menguado en calidad y en cantidad, como ha decaido en riqueza y en prestigio la aristocracia. Las clases medias absorben visiblemente a las extremas; fenómeno que en parte se debe a los progresos de la civilización, en parte se debe a las instituciones pollticas, y cuyas ventajas e inconvenientes no me propongo dilucidar”. M. Bretón de los Herreros, "La castahiera", en Los españoles, cit., p. 10.

21 "La gitana", Ibidem, p. 121.

22 Vid. H. Juretschke (Coord.), La época del Romanticismo (1808-1874). II. - Las letras. Las artes, La vida cotidiana, Madrid, Espasa-Calpe, 1989 (2ªd.), vol. XXXV (2). p. 102.

23 Curiosamente, Salas y Quiroga recrimina en "La actriz" que las mujeres se dediquen en exceso a lo que él llama "los cuidados y necesidades domésticas". En esta ocasión, lo hace para criticar la falta de profesionalidad de las actrices espaniolas pues la mayoría, sin educación dramática, actúa por tradición familiar. "No tienen éstas medios suficientes para recibir la educación de tradición o ejemplo que necesita el escenario, ni saben cuáles son los sacrificios que exige el público, en pago de sus aplausos. Buenas madres, buenas hijas, buenas esposas no es ser buenas actrices. Los cuidados y necesidades domésticas las hacen olvidar hasta el esmero que necesita la figura para conservar su lozanía." Los españoles, cit., p. 272.

24 En estos textos se aprecia el "conductismo" de sus autores. Se intentaba "dirigir" la conducta de las mujeres conforme los gustos y cánones de la época. Se les estaba indicando a las mujeres que tenfan que tener muchísimo cuidado si se pasaban en la instrucción, pues quedarian solteras -el terrible mal del siglo-. A su vez, coincidian, si no en estos textos, en otros posteriores, en que los maridos que casaban con este tipo de mujeres terminaban dominados por ellas, sin personalidad alguna. Se intentaba, en cierto modo, educar también a los varones.

Op. cit., p. 150.

26 Tras 1868, se reformularon las opiniones anteriores con respecto al tema de la educación femenina. Entre los hitos más destacados en la consecución de este derecho, pueden enumerarse: la 
fundación, en 1869, de la Escuela de Institutrices; la aparición, al año siguiente, de la Asociación para la Ensefianza de la Mujer; la creación, en 1876, de la Insticución Libre de Ensefianza; y los dos Congresos Pedagógicos de 1882 y 1892.

27 Alusión similar a esa modernidad de las costumbres adoptadas del extranjero por la que las madres se negaban a dar a luz, entre otras razones porque perdían su buena figura, se ve en "La comadre": "Pero lo que más admira es cómo las mujeres, que tanto discurren para encontrar cosas nuevas, continúan con la antigualla de parir, ni más ni menos que lo hicieron sus abuelas, a pesar de ser ésta una costumbre tan de mal tono, que hasta del nombre hacen melindre, en especial las solteronas". Los españoles, cit., p. 249.

"El ama de llaves", Ibidem, p. 52. El tipo de la fea fue una curiosa creación costumbrista. La retrató por vez primera Roberto Robert para Las españolas pintadas por los españoles (Colección de estudios acerca de los aspectos, estados, costumbres y cualidades generales de nuestras contemporáneas. Ideada y dirigida por..., Madrid, Imp. a cargo de J. M. Morete, 1871, vol. I, pp. 177-184). Adela Ginés realiza en sus Apuntes para un album del bello sexo ya citados una revalorización del tipo, siempre denostado socialmente. A su juicio, las feas pueden tener el interés de su belleza moral y el de su inteligencia, frente a las guapas, que, en muchas ocasiones, son las verdaderamente odiosas. (Vid. "La fea", op. cit., pp. 96-98.)

29 "-Mejor sería que fuese V. a cuidar de su esposo y de sus hijos, y se dejara de venir a estos sitios con los mismos chismes de ayer, profanando un día y otro la cátedra de la penitencia... ¡ Creen Vds. que es posible ser buena esposa, yendo todo el día de iglesia en iglesia, y que será mejor madre de familia la que rece mayor número de rosarios al díl". Los españoles, cit., pp. 70-71.

30 "Ha estado leyendo los papeles y le ha faltado tiempo para el tocador; pero, en cambio, está al corriente de todas las novedades de la circunstancia, de todos los sucesos pasados, presentes y por venir". Ibidem, p. 198.

31 Las colecciones costumbristas (1870-1885), Alicante, Universidad de Alicante, 1993, p. 30.

32 Las mujeres españolas, portuguesas y americanas. Tales como son en el hogar doméstico, en los campos, en las ciudades, en los templos, en los espectaculos, en el taller y en los salones. Descripción y pintura del carácter, costumbres, trajes, usos, religiosidad, belleza, defectos, preocupaciones y excelencias de la mujer de cada una de las provincias de España, Portugal y América, e ilustrada por los más notables artistas españoles y portugueses, Madrid-La Habana-Buenos Aires, Imp. y Lib. de D. Miguel Guijarro, Editor, 1872-1876, 3 vols.

Colecciones costumbristas, cit., pp. 117-118.

34 Los españoles de ogaño, colección de tipos de costumbres dibujadas a pluma por los señores..., Madrid, Lib. de Victoriano Suárez, 1872, 2 vols. Los tipos femeninos retratados reflejan, en cierto modo, la evolución de la sociedad decimonónica: "La suripanta", "La mamá de teatro", "La parroquiana de café", "La cursi", "La niñera", "La planchadora", "La enamorada de un poeta", "La peinadora", "La modista" y "La literata".

35 Madrid por dentro y por fuera. Gula de forasteros incautos. Misterios de la Corte, enredos y mentiras, verdades amargas, fotografias sociales. La familia, la calle, el paseo. Cuadros de costumbres, miserias madrileñas, lujo y babolla. Tipos de Madrid, sefioras y caballeros, politicos y embusteros. Lo de arriba, to de abajo, lo de fuera y lo de dentro. Madrid tal cual es, Madrid al pelo, Madrid en camisa, Madrid, A. de San Martin y Agustín Jubera, 1873. Los tres tipos elegidos son: "La portera", "Doria Guadalupe" y "La hora de las modistas".

36 Estas dos obras son: Los valencianos pintados por st mismos. Obra de interés y lujo escrita por varios distinguidos escritores, Valencia, Imp. de la Regeneración, de don I. Boix, 1859. Sus tipos femeninos son: "La carabasera", "La peixcaora", "La tostonera", "La revendedora", "La rifera", "La panollera" y "La valenciana"; y el Album de Galicia, Ferrol, 1897. Todos los tipos femeninos de esta colección presentan la peculiaridad de estar escritos en castellano: "La gallega", "Las mujeres del Barco" y "La señorita de aldea". 